\title{
DEVELOPMENTAL PATTERNS OF SEX DIFFERENCES IN VERBAL AND VISUOSPATIAL ABILITIES
}

\author{
Efrat Barel, \& Orna Tzischinsky \\ Department of Behavioral Sciences, The Max Stern Academic College of Emek Yezreel (Israel)
}

\begin{abstract}
The present study explored the developmental patterns of sex differences in verbal and visuospatial abilities. Three hundred and twenty-six children and adults completed a battery of six cognitive tasks including two sets of abilities: The verbal cognitive battery included verbal fluency and short-term memory tasks. The visuospatial battery included mental rotation, localization, and form completion tasks. Results showed significant sex $\times$ age interaction on the mental rotation task, with men outperforming women in the 3-D task, but with no sex differences shown in childhood in the 2-D task. Sex differences in verbal fluency were found with girls and women outperforming boys and men in this task. Findings are discussed within an integrative approach of biological as well as environmental factors.
\end{abstract}

Keywords: Cognitive abilities, sex differences, developmental pattern.

\section{Introduction}

The present study aimed at investigating sex differences in various verbal and visuospatial abilities in childhood and adulthood. Sex differences in cognition received consistent support in adults. Men outperform women in visuospatial abilities, whereas women outperform men in verbal abilities (Halpern, 2012; Hines, 2004). Although research focusing on visuospatial abilities found that men outperform women on many tasks (e.g., navigation strategies and geographic orientation; Driscoll, Hamilton, Yeo, Brooks, \& Sutherland, 2005), the largest effect size has been found on mental rotation (e.g., Barel \& Tzischinsky, 2017; Burton \& Henninger, 2013; Hines et al., 2003; also see Linn \& Petersen, 1985; and Voyer, Voyer, \& Bryden, 1995, for meta-analyses). Women have been found to outperform men in verbal abilities, especially verbal memory (e.g., Bleecker, Bolla-Wilson, Agnew, \& Meyers, 1988; Kramer, Delis, \& Daniel, 1988) and verbal fluency (e.g., Burton \& Henninger, 2013; Weiss, Kemmler, Deisenhammer, Fleischhacker, \& Delazer, 2003). In other areas, such as vocabulary, verbal reasoning, and line orientation (Kimura, 2002), the findings are inconsistent.

In comparison with the consistency found in adults for sex differences in cognitive abilities, the age at which these differences emerge is unclear. Empirical evidence for sex differences in cognitive abilities prior to puberty did not produce unequivocal findings. Some studies have suggested that sex differences in verbal abilities appear early in life. For example, Lutchmaya, Baron-Cohen, and Raggatt (2002) demonstrated that girls show superiority to boys in vocabulary development, with 2-year-old girls using significantly more words than boys. Zambrana, Ystrom, and Pons (2012) documented sex differences in language comprehension at 18 and 36 months of age favoring girls at both time points.

Studies exploring individual differences and developmental aspects in visuospatial abilities used various tasks, including mental rotation, the Water Level Test, and block design. Studies of prepuberty children provided mixed results with regard to sex differences in visuospatial abilities. Some studies have demonstrated that the male advantage in mental rotation is apparent as early as infancy (Moore \& Johnson, 2008; Quinn \& Liben, 2008). Nevertheless, not all infant studies provided support for sex differences in mental rotation task in infancy (e.g., Hespos \& Rochat, 1997). In a similar vein, studies of preschool and school-aged children also provided mixed results. For example, Frick, Ferrrara, and Newcombe (2013) found sex differences in a mental rotation task. Palejwala and Goldenring Fine (2015) have examined, among others, sex differences in visual processing via block design and object assembly tasks, and found that sex differences at ages 2 to 3 were absent, whereas they emerged at ages 4 to 7 .

Sex differences in short-term memory in children usually do not generate significant results. For example, no sex differences were found in a picture memory task and in a location memory task in children aged 2 to 7 (Palejwala \& Goldenring Fine, 2015). In contrast, Keith, Reynolds, Roberts, Winter, 
and Austin (2011) reported sex differences in short-term memory with the use of a latent variable approach. Girls outperformed boys at ages 5 to 13, whereas boys outperformed girls at ages 14 to 17 .

The accumulated evidence regarding sex differences in cognitive abilities throughout the life span suggests that sex differences in cognition are magnified or become more common during adolescence (Herlitz, Reuterskiöld, Lovén, Thilers, \& Rehnman, 2013). The underlying mechanism for the developmental pattern of sex differences in cognitive abilities involves a complex interplay between biological and environmental variables. Among the environmental variables, play experiences (e.g., Caldera et al., 1999) and socio-cultural gender stereotypes (Quaiser-Pohl \& Lehmann, 2002) have been suggested as important factos related cognitive skills. Among the biological variables, endocrine factors such as sex hormones have been suggested as important factors (Halpern, 2012). Sex hormones, including androgens, estrogens, and progestins, can affect a wide range of organs, including the brain. Their greatest effect occurs during two sensitive periods in development: The first is during the prenatal and/or neonatal period, the second during the postnatal period (Collaer, Reimers, \& Manning, 2007; Halpern, 2012). It has been suggested that these sensitive periods in hormonal secretion are associated with sex differences in cognitive abilities (Hines, 2011; Kimura, 2002).

In sum, previous studies have suggested that sex differences in cognitive abilities are magnified and established during adolescence and adulthood, and are proposed to be mediated by neuroendocrine development in adolescence. The present study was designed to investigate developmental patterns in sex differences in cognitive abilities.

The hypotheses are as follows:

a. It is hypothesized that a Sex $\times$ Age interaction on visuospatial abilities is found in adults, with men outperforming women, and no sex differences in children.

b. It is hypothesized that sex differences in verbal abilities are found with female participants outperforming males, in both children and adults, with a magnified effect in adults.

\section{Methods}

\subsection{Participants}

Three hundred and twenty-six children and adults participated in the present study. One hundred and fifty-seven were undergraduate students from various departments: behavioral sciences (Psychology, Education), social sciences (Sociology and Anthropology, Information Systems, Economics, Accounting, and Management), and communication, at a college in the north of Israel. Eighty of the participants were female $\left(\mathrm{M}_{\mathrm{age}}=26.04 \pm 3.45\right)$ and seventy-seven were male $\left(\mathrm{M}_{\mathrm{age}}=26.18 \pm 2.78\right)$. One hundred and sixty-nine were children in grades 4 and 5 from 4 schools in the north of Israel (two schools from a medium-high socioeconomic status background, and two schools from a low socioeconomic status background). Eighty-seven of the participants were female $\left(\mathrm{M}_{\text {age }}=10.34 \pm 0.61\right)$ and eighty-two were male $\left(\mathrm{M}_{\mathrm{age}}=10.45 \pm 0.61\right.$; see Figure 1). All participants were right-handed according to their subjective reports.

Adult participants were recruited through advertisements at the college, and did not receive monetary compensation for their participation. Participants gave their informed consent. Children were recruited as part of their school assignment, following their parents providing their consent for their child's participation.

\subsection{Measures}

Cognitive test battery -Six types of tasks were presented to the participants: three verbal and three visuospatial cognitive tasks (Gordon \& Harness, 1977): Serial sounds; Serial digits; Verbal fluency; Mental rotation (2D and 3D stimuli); Localization; Form completion.

\section{Results}

\subsection{Hypothesis a: Sex $\times$ Age interaction on visuospatial abilities}

There was a statistically significant interaction between sex and age group on mental rotation $\left(\mathrm{F}(1,317)=8.78, \mathrm{p}<.01, \eta_{\mathrm{p}}{ }^{2}=.03\right)$. Adult males outperformed adult females $(\mathrm{p}<.001)$, whereas there were no sex differences in children $(\mathrm{p}>.05)$.

\subsection{Hypothesis b: Sex differences on verbal abilities}

For verbal fluency, the difference between males and females was significant, $\left(\mathrm{F}(1,322)=26.27, \mathrm{p}<.001, \eta_{\mathrm{p}}{ }^{2}=.08\right)$, with female participants outperforming males. 


\section{Discussion}

The present study assessed sex differences in visuospatial and verbal abilities in children and adults. The hypotheses were partially supported. Sex differences in verbal fluency were identified in childhood as well as in adulthood, with females outperforming males. This finding is in accord with previous results demonstrating the emergence of sex differences in verbal abilities in childhood, with no indication of these differences magnified throughout development (Herlitz et al., 2013). The findings suggest that sex differences in verbal abilities emerge before puberty and imply that the source of these differences should be sought early in development. Findings on other verbal tasks (short-term memory tasks) failed to produce significant results. This is line with the empirical evidence with regard to sex differences in memory tasks in children, usually implying no sex differences (e.g., Palejwala \& Goldenring Fine, 2015).

With regard to visuospatial tasks, empirical literature reported consistently that the largest effect size of sex differences was found for the mental rotation task (Levine, Foley, Lourenco, Ehrlich, \& Ratliff, 2016). The present study revealed that sex differences are not apparent in children. In adults, our findings supported previous studies demonstrating a large effect size $(\mathrm{d}=0.84)$. Previous meta-analyses (Linn \& Peterson, 1985; Voyer et al., 1995) confirmed that there is substantial male advantage on mental rotation tasks, and pointed out that the tasks which involve 3D rotations (as opposed to rotating simpler shapes in the picture plane) produce the largest effect size, probably due to females' difficulty to mentally rotate objects in depth. In children, the present study used 2D stimuli, which have not produced significant sex differences. Several studies tested children's performance on various 2D stimuli using animal drawings (Kucian, von Aster, Loenneker, Dietrich, Mast, \& Martin, 2007) or other familiar objects (Ruthsatz, Neuburger, Jansen, \& Quaiser-Pohl, 2015), alphanumeric stimuli (Hoyek et al., 2012), or abstract characters (Hoyek et al., 2012; Kail, Pellegrino, \& Carter, 1980). They have demonstrated that various 2D stimuli differ in their difficulty level. Performances for familiar 2D stimuli (e.g., animal drawings or alphanumeric stimuli) were found to elicit higher accuracy scores and shorter response times as opposed to abstract characters (e.g., Kail et al., 1980). Kail et al. (1980) proposed that abstract characters are unfamiliar to both children and adults as opposed to familiar (e.g., alphanumeric) stimuli.

The underlying mechanism for the developmental pattern of sex differences' emergence in mental rotation received much attention from a biological perspective, especially the role of sex hormones and sex differences in brain structure and function. The most notable influence of sex hormones occurs during sensitive periods in development: prenatal and postnatal (Collaer et al., 2007; Halpern, 2012). Puberty has been suggested as a sensitive period of sex hormone-dependent brain organization, with increased levels of sex hormones secretion influencing changes in cognitive performance (Berenbaum \& Beltz, 2011). In a recent review, Levine et al. (2016) have postulated an integrative approach, including biological as well as environmental factors accounting for sex differences in mental rotation abilities. The suggested model could explain the differences in magnitude from childhood through adulthood in sex differences in mental rotation shown in the present study, as well as in former studies. One possible integrative attempt regarding Gene $\times$ Environment interaction influencing mental rotation performance suggests that the preliminary male advantage in these tasks led them to become more interested in these activities, which in turn led to a greater spatial advantage (Pezaris \& Casey, 1991). This notion is also supported by an evolutionary approach suggesting that differing evolutionary forces imposed on human males and females resulted in differences in anatomy followed by sexual differences in function (Lenroot \& Giedd, 2010). Males engaged in more spatially demanding tasks and, therefore, differential corresponding neuroendocrine infrastructures were needed to develop in human males and females.

To summarize, the present findings suggest that whereas females outperform males in verbal fluency throughout development, sex differences favoring males occur after puberty. Although the findings regarding verbal fluency are not consistent across studies, studies concerning the emergence and increase of sex differences in spatial abilities, and especially mental rotation ability, seem consistent (Berenbaum \& Beltz, 2011). Four decades ago, Waber (1976) postulated that sex differences in cognitive abilities could be explained by maturation rate. He suggested that through the mediation role of the development of hemispheric specialization, late maturers have better spatial abilities, whereas early maturers have better verbal abilities. The present findings provide support for this suggestion.

The present study has some limitations. First, the nature of the mental rotation task used for children and adults in the current study was different. Although the abstract 2D measure for mental rotation capability in children has been validated as capturing a high level of complexity of mental rotation ability, still, future studies are needed for developing 3D stimuli appropriate for children. Second, we have not controlled for the time of day or stage in the menstrual cycle of data collection. Since testosterone, estrogen, and progesterone vary across day time and the menstrual cycle, further studies 
should control for these factors. Third, although the adult sample consisted of participants from various departments (including social as well as formal sciences), future studies should still examine a wide range of study disciplines, especially from natural sciences and STEM fields in order to uncover the influence of field orientation and field expertise on the magnitude of sex differences in various cognitive abilities.

Table 1. Means (SD, Z-Scores, Raw Scores) and Cohen's D For Sex Differences in Verbal and Visuospatial Cognitive Abilities.

\begin{tabular}{|c|c|c|c|c|c|c|}
\hline & & Children & & & Adults & \\
\hline & Boys $(\mathrm{N}=82)$ & Girls $(\mathrm{N}=87)$ & $\mathrm{d}$ & Men $(\mathrm{N}=77)$ & $\begin{array}{l}\text { Women } \\
(\mathrm{N}=80)\end{array}$ & $\mathrm{d}$ \\
\hline Serial Sounds & $81.96(37.66)$ & $91.98(43.07)$ & 0.25 & $111.09(55.34)$ & $114.68(42.21)$ & 0.08 \\
\hline Serial Digits & $7.72(2.57)$ & $7.95(2.56)$ & 0.32 & $9.58(1.06)$ & $9.88(1.58)$ & 0.23 \\
\hline Verbal Fluency & $17.80(6.47)$ & $21.93(6.65)$ & $0.63 * * *$ & $39.43(10.69)$ & $44.88(10.82)$ & $0.50 * *$ \\
\hline Mental Rotation & $15.41(5.74)$ & $14.98(5.54)$ & 0.14 & $15.23(4.10)$ & $11.35(4.57)$ & $0.84 * * *$ \\
\hline Localization & $1.93(0.36)$ & $2.03(0.45)$ & 0.21 & $0.98(0.74)$ & $1.06(0.72)$ & 0.14 \\
\hline Form Comletion & $13.43(7.15)$ & $13.67(7.17)$ & 0.00 & $12.18(4.38)$ & $11.34(4.33)$ & 0.15 \\
\hline
\end{tabular}

Note. The localization score is higher for poorer performance

$* * \mathrm{p}<.01 \quad * * * \mathrm{p}<.001$

\section{References}

Barel, E., \& Tzischinsky, O. (2017). The role of sex hormones and of 2D:4D ratio in individual differences in cognitive abilities. Journal of Cognitive Psychology, 29, 497-507.

Berenbaum, S. A., \& Beltz, A. M. (2011). Sexual differentiation of human behavior: Effects of prenatal organizational hormones. Frontiers in Neuroendocrinology, 32:10.

Bleecker, M. L., Bolla-Wilson, K., Agnew, J., \& Meyers, D. A. (1988). Age-related sex differences in verbal memory. Journal of Clinical Psychology, 44, 403-411.

Burton, L. A., \& Henninger, D. (2013). Sex differences in relationships between verbal fluency and personality. Current Psychology, 32, 168-174.

Caldera, Y. M., Mc Culp, A., O’Brien, M., Truglio, R. T., Alvarez, M., \& Huston, A. C. (1999). Children's play preferences, construction play with blocks, and visual-spatial skills: are they related? International Journal of Behavioral Development, 23, 855-872.

Collaer, M. L., Reimers, S., \& Manning, J. T. (2007). Visuospatial performance on an internet line judgment task and potential hormonal markers: Sex, sexual orientation, and $2 \mathrm{~d}: 4 \mathrm{~d}$. Archives of Sexual Behavior, 36, 177-192.

Collins, D. W., \& Kimura, D. (1997). A large sex difference on a two-dimensional mental rotation task. Behavioral Neuroscience, 111, 845-849.

Driscoll, I., Hamilton, D. A., Yeo, R. A., Brooks, W. M., \& Sutherland, R. J. (2005). Virtual navigation in humans: The impact of age, sex, and hormones on place learning. Hormones and Behavior, 47, 326-35.

Frick, A., Ferrara, K., \& Newcombe, N. S. (2013). Using a touch screen paradigm to assess the development of mental rotation between 3.5 and 5.5 years of age. Cognitive Processing, 14, 117-127.

Gordon, H. W. (1986). The cognitive laterality battery: Tests of specialized cognitive function. International Journal of Neuroscience, 29, 223-244.

Gordon, H. W., \& Harness, B. Z. (1977). A test battery for diagnosis and treatment of developmental dyslexia. DASH Speech and Hearing Disorders, 8, 1-7.

Gordon, H. W., \& Lee, P. A. (1993). No difference in cognitive performance between phases of the menstrual cycle. Psychoneuroendocrinology, 18, 521-531.

Halpern, D. F. (2012). Sex differences in cognitive abilities (4th ed.). New York, NY: Psychology Press.

Halpern, D. F., Benbow, C. P., Geary, D. C., Gur, R. C., Shilbey Hyde, J., \& Gernsbacher, M. A. (2007). The science of sex differences in science and mathematics. Psychological Science in the Public Interest, 8, 1-51. 
Herlitz, A., Reuterskiöld, L., Lovén, J., Thilers, P. P., \& Rehnman, J. (2013). Cognitive sex differences are not magnified as a function of age, sex hormones, or puberty development during early adolescence. Developmental Neuropsychology, 38, 167-179.

Hespos, S. J., \& Rochat, P. (1997). Dynamic mental representation in infancy. Cognition, 64, 153-188.

Hines, M. (2004). Brain gender. Oxford, England: Oxford University Press.

Hines, M. (2011). Gender development and the human brain. Annual Review of Neuroscience, 34, 69-88.

Hines, M., Fane, B. A., Pasterski, V. L., Mathews, G. A., Conway, G. S., \& Brook, C. (2003). Spatial abilities following prenatal androgen abnormality: Targeting and mental rotations performance in individuals with congenital adrenal hyperplasia. Psychoneuroendocrinology, 28, 1010-1026.

Hoyek, N., Collet, C., Fargier, P., \& Guillot, A. (2012). The use of the Vandenberg and Kuse Mental Rotation Test in Children. Journal of Individual Differences, 33, 62-67.

Kail, R., Pellegrino, J., \& Carter, P. (1980). Developmental changes in mental rotation. Journal of Experimental Child Psychology, 29, 102-116.

Keith, T. Z., Reynolds, M. R., Roberts, L. G., Winter, A. L., \& Austin, C. A. (2011). Sex differences in latent cognitive abilities ages 5 to 17: Evidence from the Differential Ability Scales (2nd ed). Intelligence, 39, 389-404.

Kimura, D. (2002). Sex hormones influence human cognitive pattern. Neuroendocrinology Letters, 23, 68-77.

Kramer, J. H., Delis, D. C., \& Daniel, M. (1988). Sex differences in verbal learning. Journal of Clinical Psychology, 44, 907-915.

Kucian, K., von Aster, M., Loenneker, T., Dietrich, T., Mast, F. W., \& Martin, E. (2007). Brain activation during mental rotation in school children and adults. Journal of Neural Transmission, 114, 675-686.

Lenroot, R. K., \& Giedd, J. N. (2010). Sex differences in the adolescent brain. Brain and Cognition, 72, 46-55.

Levine, S. C., Foley, A., Lourenco, S., Ehrlich, S., \& Ratliff, K. (2016). Sex differences in spatial cognition: Advancing the conversation. WIREs Cognitive Science, 7, 127-155.

Linn, M. C., \& Petersen, A. C. (1985). Emergence and characterization of sex differences in spatial ability: A meta-analysis. Child Development, 56, 1479-1498.

Lutchmaya, S., Baron-Cohen, S., \& Raggatt, P. (2002). Foetal testosterone and vocabulary size in 18 and 24 month old infants. Infant Behavior and Development, 24, 418-424.

Moore, D. S., \& Johnson, S. P. (2008). Mental rotation in human infants: A sex difference. Psychological Science, 19, 1063-1066.

Palejwala, M. H., \& Goldenring Fine, J. (2015). Gender differences in latent cognitive abilities in children aged 2 to 7 . Intelligence, $48,96-108$.

Pezaris, E., \& Casey, B. M. (1991). Girls who use "masculine" problem-solving strategies on a spatial task: Proposed genetic and environmental factors. Brain and Cognition, 17, 1-22.

Quaiser-Pohl, C., \& Lehmann, W. (2002). Girls' spatial abilities: Charting the contributions of experiences and attitudes in different academic groups. British Journal of Educational Psychology, 72, 245-260.

Quinn, P. C., \& Liben, L. S. (2008). A sex difference in mental rotation in young infants. Psychological Science, 19, 1067-1070.

Ruthsatz, V., Neuburger, S., Jansen, P., \& Quaiser-Pohl, C. (2015). Cars or dolls? Influence of the stereotyped nature of the items on children's mental-rotation performance. Learning and Individual Differences, 43, 75-82.

Voyer, D., Voyer, S., \& Bryden, M. P. (1995). Magnitude of sex differences in spatial abilities: A meta-analysis and consideration of critical variables. Psychological Bulletin, 117, 250-270.

Waber, D. P. (1976, May). Sex differences in cognition: A function of maturation rate? Science, 192(4239), 572-574.

Weiss, E. M., Kemmler, G., Deisenhammer, E. A., W. Fleischhacker, W. W., \& Delazer, M. (2003). Sex differences in cognitive functions. Personality and Individual Differences, 35, 863-875.

Zambrana, I. M., Ystrom, E., \& Pons, F. (2012). Impact of gender, maternal education, and birth order on the development of language comprehension: A longitudinal study from 18 to 36 months of age. Journal of Developmental and Behavioral Pediatrics, 33, 146-155. 